\title{
Same bed, different dreams: The mismatched expectations about proofreading in the writing center
}

Kim, Juhi $\bowtie$

Miami University, USA (juhikim.1@gmail.com)

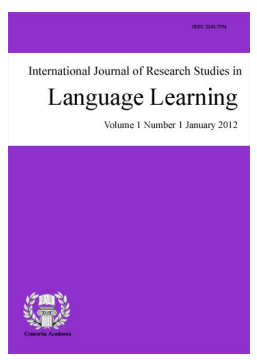

Accepted: 5 July 2018

ISSN: 2243-7754 Online ISSN: 2243-7762

\section{Abstract}

No proofreading is one of the major policies of the university writing center. The no proofreading policy is oriented from the process-oriented writing instruction that is represented with the non-directive, student-centered approach. However, for L2 students who are not familiar with the process-oriented instruction due to different social and educational backgrounds and seek immediate help to improve their writing, the university writing center does not provide the needed help to improve the L2 students' writing. For them, the Center's instructional policy is not just ineffective but also incomprehensible as well. In this regard, the discrepancy of L2 students' expectations about the work of the writing tutorial and the instructional philosophy of the university writing center becomes a major obstacle of the work of the writing tutorial with L2 writers. Thus, this study investigates how L2 writers experience the writing instruction of the Center and what happens in their first encounter with the work of the tutorial. By examining their talk in the writing tutorial and their experience of writing instruction in the writing center, this study aims to show how their different expectations of the writing instruction are played out and shaped for the work of the writing tutorial.

Keywords: proofreading; grammar instruction; writing tutorial; writing center; L2 writer; international student 


\section{Same bed, different dreams: The mismatched expectations about proofreading in the writing center}

\section{Introduction}

More and more students from overseas come to the U.S. to pursue academic success. Encountering people who speak different languages on campus has become a common, everyday experience. According to a report from the U.S. Immigration and Customs Enforcement's (ICE) Homeland Security Investigations (HSI) in 2016, 1.11 million international students were enrolled in U.S. schools, which is a 5.5 percent increase in the number of international students since July 2015. This means that a considerable number of the population enrolled in U.S educational institutions study in their second or foreign language, not in their native language. In this regard, the growing numbers of international students on campus are not just a sign of a global education or cultural diversity. It is a significant issue about language education that requires more attention on the L2 students to achieve their academic success in the U.S.

Although the international students are admitted to the U.S. educational institutions with an acceptable level of standardized English test score, those who studied English only from the formal educational system in their home countries were not trained enough for the level of academic writing the university courses require. Also, their oral/aural skills are still developing. Thus their language ability becomes most critical for L2 students when they come to the U.S. to study and it is not extreme to say that their English language ability, particularly, their writing ability in English determines their academic success in the U.S. University. Also considering the fact that 77 percent of international students come from Asia (U.S. Immigration and Customs Enforcement, 2016), the difficulties that the international students would experience are not just their English language ability or the lack of writing practice. In addition to the cultural difference, the difference from the different instructional styles in a new educational system can also create confusion and misunderstanding during their learning process.

The difficulties in working on the course assignment for writing come in many different aspects: from higher-order concerns such as understanding the assignment, choosing the appropriate topic to work with, developing the content to fit the requirements of the assignment, to the lower-order concerns about grammar, punctuation and sentence-level syntax. Higher-order (global) concerns are directly related to the content of the paper, which is about the subject of the class, and the lower-order (local) concerns are about the work to refine the accuracy and fluency of their writings. The content of disciplinary knowledge is the subject of the class that the students are evaluated from the assignment. They are pressured with a double amount of burden to acquire the disciplinary knowledge that includes higher-order concerns and writing proficiency such as grammar accuracy and fluency for good performance. In this circumstance, those who are concerned about their writing proficiency try to complete their assignment in advance and seek help to refine their writing for its accuracy and fluency, which is proofreading, from somewhere such as the Writing Center. Those who are willing to put that amount of effort into their writings to refine their performance are the students who are more interested in their writing performance and more enthusiastic to perform better for a good academic grade.

However, this approach does not work well with the pedagogical philosophy of the contemporary writing center. The university writing centers have evolved from the traditional old-style fix-it-shop to the research centers for teaching of writing, which emphasizes the process of writing instead of the product of writing. No proofreading and process-oriented instruction are the major policies of the contemporary writing center. From the Center's view, the need for a final check to refine the grammar accuracy and fluency for writing does not match what the writing center pursues for writing instruction. The discrepancy between their expectations and the Center's new approach to writing instruction creates a cacophony in the work of the tutorial and becomes a cause of tension and conflict between the tutor and the student. 
Same bed, different dreams: the mismatched expectations about proofreading in the writing center

In this regard, investigating how the tutor and L2 writers interact with each other during the tutorial is important to understand how to help L2 writers to improve their writing ability in the process of their academic socialization. Mainly, knowing how they interact in their first encounter and how they work with the discrepancy of their expectations for the work of tutorial is essential to understand how to work with L2 writers and the nature of L2 writing development. Therefore, in this paper, I will give an overview the literature about the writing center's pedagogical philosophy, L2 writers' characteristics in their development of writing, and their perception about the process of writing. Transcript analyses of two exemplary cases of tutorials will follow with the distinctive features that contain the nature of the subtle tension about proofreading that L2 writers desire from the writing tutorial and the resistance from the tutor against doing proofreading.

\section{Literature Review}

\subsection{The Writing Center's Philosophy and No Proofreading Policy}

Writing centers have been a place to help the students' writing ability on campus for decades. At the inception of the institutional history, writing centers were devised to improve the domestic students' academic writing skills and the instruction was focused on remediation of their writing to clean the errors. However, along with the shift of the literacy education, their work and pedagogy for writing instruction have been evolving toward a process-oriented instruction that emphasizes collaboration during the writing instead of the product of writing. The writing-as-a-process approach for instruction emphasizes collaborative engagement between the tutor and the student. This approach puts the priority of the writing instruction on interactions through the conversation between the tutor and the student that requires the student's engagement to the work of writing through negotiation (Lunsford, 1991).

The core of the writing instruction exists on the interactional conversation during the tutorial as a process-for-writing, not as a product of writing. North (1984) claims, "Writing centers produce a better writer, not better writing (p. 438)". The approach of writing as a process, not as a product corresponds with what North said, "producing a better writer, not better writing." Writing is a socially negotiated collaborative process, and writing instruction is beyond fixing problems (Lunsford, 1991). Supported by these claims, the major policy that represents the new perspective of writing instruction of the writing center is the no proofreading policy. However, for the international students who are not familiar with this new instructional style, the no proofreading policy is not just ineffective but incomprehensible. In this regard, process-oriented instruction, which is characterized by a non-directive, student-centered approach has brought on issues about the methodological applicability with L2 writers regarding directive vs. non-directive and explicit vs. inexplicit instruction (Ling, 2015; Başöz, 2014; Myers, 2003; Harris \& Silva, 1993). The dispute about the efficiency of error-correction during writing instruction was developed further with regard to proofreading and grammar instruction.

For the international students who are familiar with teacher-centered, traditional remediation-focused instructional setting and who never had worked in one-to-one conversation based writing instruction previously, the new instructional style can be perceived as an obstacle that prevents them from seeking help on their visit. This misunderstanding about the work of the writing center has created tension and conflict between the tutor and the tutee in moving on for the work of the writing tutorial (Kim, 2014).

\subsection{L2 writers' Learning Experience in English}

Along with the increasing population of international students in American University nowadays, roughly half of the population who visit writing centers are second language learners. Many are new to the US educational system, and their English competence is still developing as second language learners. Particularly those who come from the countries that speak English as a foreign language (EFL) experience burden and frustration in their adjustment to the new cultural and educational environment. The students from an EFL environment lack input in their exposure to the English language in their previous learning experience; and this 
environmental difference in their learning influences them to become an "eye learner" who studies English through their eyes by studying vocabulary, verb forms, and grammar rules. They learn English grammar as rule learning for test preparation and as a consequence, their writing skills are limited from the lack of the writing experience. Compared to the ESL students, "ear learners" who learn English as their second language in an English speaking country, the international students' aural/oral skills are weak for communication (Dvorak, 2016; Linville, 2009, Reid, 1998).

In this regard, conversational instruction during the tutorial can be burdensome to those who lack oral fluency and aural comprehension. The international students who are familiar with the teacher dominant instructional setting can be confused the one-to-one instructional setting regarding the purpose and the expected roles for the work of the tutorial (Ferris \& Hedgcock, 2014; Ferris, 2009, 2003).

\subsection{Lack of Understanding of Process-Oriented Writing Instruction}

In addition to social, cultural and linguistic differences, the international students' prior experience of English writing becomes another hindrance to the new instructional style. A writing tutorial with a completed draft is a part of the process of revision. By getting feedback from a second reader through the instructional conversation, the writer can reorganize their ideas for the argument by clarifying and reformulating. In this way, the process of writing for revision through the tutorial is not lineal; it becomes a discursive process.

However, L2 writers perceive revision as an error-correcting activity from their texts. They believe that they should clean all of the mistakes from their final draft through error-correcting and proofreading for revision. Their intentions for revision toward error-free paper occur similarly across languages (Takagaki, 2003). In this circumstance, for those who are familiar with the teacher-centered and product-oriented instructional setting, the process-oriented approach of writing that includes the various stages of writing instruction - prewriting, drafting and multiple revisions with feedback - is not just challenging but time-consuming (Min, 2016; Liu, 2016; Deckert, 2009; Porte, 1997; Parkhurst, 1990; Lai, 1986).

L2 writers' learning experience and their language proficiency have a significant influence on their tutorial interactions during the instruction. When they encounter dissonance from the cross-cultural miscommunications and the mismatched expectations for the work of the tutorial, both the L1 tutor and the L2 writers experience dissatisfaction and frustration with the work of the tutorial and it becomes a serious hindrance for continuing the work of writing. Thus in the following section, I will present two exemplary cases that show the mismatched expectations between the tutor and the tutee about the work of the tutorial and how they steer the work to move on for the work of the tutorial.

\section{Data and Method}

The selected tutorials in this study were collected from the writing center in a major Midwestern university in the US with IRB permission as part of my fieldwork. The tutors in this study were graduate students who had been tutoring for three years in the writing center at the time that the data were collected. Both tutors are U.S. born, native English speakers. The tutees were undergraduate students from South Korea and China. The tutees in this study were novices who did not have previous experience with the writing tutorial in the setting of the university writing center.

As an analytical framework, conversation analysis (CA) was employed to examine the participants' social actions that are accomplished through talk in their management of the interactional context. CA accounts for a learner's interactional competence and identifies the nature of learning interaction by providing the analytical potential of the fine-grained transcripts of communicative events. CA shows how meaning is constructed as socially distributed phenomena through the interactional practice (Markee, 2009, 2004, 2000). Particular interest was given to the sequential organization of the participants' talk and their interaction, which enable the description of the vivid details of the enactment of the work for the instructional event of the writing tutorial. 
The selected exemplary cases reveal the core of the conflict and the tension about proofreading between the L1 tutor and the L2 writer during the tutorial. The cases were transcribed by following the convention of conversation analysis (Sacks, Schegloff, \& Jefferson, 1974). The discussion of the transcript analysis is provided with the ethnographic data about the participants in the writing center.

\section{Analysis}

As discussed previously, many international students do not have experience with a writing center in their home countries where assistance in writing is provided. Due to this lack of knowledge and experience with a writing center, many of them come to the Center thinking of it as a fix-it-shop where they can get a grammar check or immediate help to make their paper better. This belief is the same as what the traditional remediation-focused writing center did, and it seems most logical for them to get help for their writing.

The first case is how the tutor steers the first-time visiting tutee who wants to get proofreading to the way that the Center can provide for instruction. The second case is how a second-time visiting tutee steers the tutor to do proofreading for her draft. By examining these two cases, I will show how the two different expectations about the work of the tutorial between the tutor and the tutee are played out during the tutorials and how they maintain the work of the tutorial.

\section{Case 1: We don't proofread}

Sang-Jin is a first-time visiting tutee to the writing center. He visits the Center to fulfill the class requirement for the course English 110. English 110 is a mandatory course for all freshmen both native and non-native English speakers. In order to take this course, the international students have to complete English 107 or 108 in the ESL program. For international students, English 110 is the first mainstream English course. He is an undergraduate student from South Korea and the tutor, Bill, is a graduate student who is a native speaker of English. He has tutored for three years in the writing center. Sang-Jin asked for a grammar check for his paper and his request was rejected by the tutor. The names of the tutors and the tutees used in this analysis are all pseudonyms (T: Tutor, C: Client -Tutee or Student).

\section{Transcript 1-1}

T: Okay So (.2) What are we workin o:n?

C: I'm taking a: English one hunduredu cra:ss

T: Okay

C: A:n (.1) in- in the crass a- I hav- so:m (.2) a- assignment

an I- I hav tu: I have tu: visit here an get tutorial (.)

this is (.) e::h the- the mission in the crass

T: Um-hm

C: (.) An so: (.1) this is the shilabus

T: Okay

C: ((C, takes out the syllabus and points at the line $))$ Here (3.0)

((reading from his syllabus $)) *($ Over here $) *$ must have visid-id the riting center an least one riting state $(.1)(. h)$

[So now- now(.)

$\mathrm{T}: \quad$ [Okay so thisiz- but thisiz- for English one ten

$\mathrm{C}: \quad=$ Yes

$\mathrm{T}$ : And you are in one ten?

$\mathrm{C}: \quad=$ Yes

T: (.hh) OK (.)

C: ((C. puts the syllabus back in the folder and takes out his paper out)) A::n the(.3) This- my(.) full page drafut

$\mathrm{T}: \quad=$ Okay

22 C: I- I- I wana:: a: get tutorial (.1) wi- *the-* eh- cheking(.) e:h- grammar

$23 \mathrm{~T}: \quad=$ Okay (.) We don't proofread (.1) 
In line 1, Bill asks "What are we workin o:n?" This is a question of 'why are you here?' Sang-Jin's formulations of 'why I'm here' follow in lines 2, 4-6 and 8. He introduces his class, the assignment he brought along, and the requirement of visiting the writing center for a tutorial. Then he pulls out his syllabus. Bill gives him continuers in lines 3, 7 and 9. Sang-Jin shows the syllabus to Bill and reads out loud the line saying that visiting the writing center is required. Then he initiates his formulation to a conclusive summary in line 13, "So now- now(.)" and it is overlapped with the Bill's receipt of Sang-Jin's formulation. Bill sees Sang-Jin's formulation of why I'm here was done and now he tries to check his understanding of San-Jin's formulation in line 14.

Bill checks the class that Sang-Jin came from as "English one ten." The students from English 110 are a major part of the clientele of the writing center. Bill is familiar with the class and their writing assignments. Sang-Jin replies with an immediate agreement to the tutor. Bill is making sure of the class name as "one ten" (line 16), not "one hundred" as Sang-Jin introduced in line 2. Again, Sang-Jin replies with an immediate agreement to the tutor. Then Bill accepts it with confirmation. The understanding check for both tutor and the tutee was done and confirmed with each other. Sang-Jin now takes out his paper and introduces it as his "full page draft" in lines 19-20. Bill gives an immediate acceptance to Sang-Jin's action. He now expects to see Sang-Jin's draft as well (line 21). Followed by Bill's acceptance of the draft, Sang-Jin directly indicates how he wants to be helped: it is to 'get a tutorial that will check his grammar' in line 22.

Sang-Jin provided all necessary information about his assignment, and he made a clear formulation of how he wants to be helped - checking grammar - for his assignment, which is perfectly reasonable from his perspective. However, it is a task that the writing center does not provide. Bill immediately refuses the request by saying "We don't proofread" (line 23). Sang-Jin's formulation of how he wants to be helped was rejected immediately after he requested.

\section{Transcript $1-2$}

$24 \quad \mathrm{U}: \mathrm{m}$ we can talk about grammar but we-

$25 \quad 1$ have to actually talk about (.) the grammar

26 T: U:m (.3) Okay(.) Other than grammar(.)

27 What ar- do you have any concerns about this particular paper?

28 C: H:m hm (h) um- uh- usually u::h I- I'm conpusing to use some-some

29 berb grammar (.) u.m maybe (.5)

30 Pas- e:h the pas- past (.) a:n da: presen(.) an puture

31 T: Um-hm

32 C: An a- a- alreiz conpuzing for example have been(.) a:n da habin pipi (.5)

$33 \quad$ A:n da tsa(.)

34 So (.3) In the- In the point I- I- I wanna get tutorial

35 T: (.2) Okay(.2) Um. Alright (.) So(.2) If I- If I understood correctly

36 you are concerned perhaps(.) a little bit about (.5) tense

37 C: $=$ Yes

38 T: An (.) Okay U:m (.) now

39 You just (.) you yu- you jü-st (.) I am gonna go ahead a:n

40 You've probably seen this explained a number of ways...

Instead, Bill offers what they can do with grammar instead of proofreading. That is "I (the tutor) have to actually talk about (.) grammar" (line 25). Having rejected the request of checking grammar, Bill introduces what the writing center policy permits regarding grammar. Sang-Jin's formulation of why I'm here cannot be accepted. Bill asks him for another formulation of 'why I'm here' in line 27, which is the same initiating question that he asked in line 1. Sang-Jin now makes a new formulation of his concerns about grammar, specifically 'verb tense, " "past and present and future" (lines 29-30) and "have been p.p." (line 32).

Following Bill's suggestion that "they can talk about grammar and he (the tutor) has to actually talk about (.) grammar" (lines 24-25), Sang-Jin revises his formulation of how he wants to be helped so that they can actually talk about grammar, specifically verb tense. There are some interesting things to notice in this transcript. By the 
clear rejection of the proofreading request and the tutor's suggestion of what they can do, the tutee revised his request immediately as the tutor suggested in a way that can be acceptable to the work of the writing center. Other than that, this first-time tutee does not know how to answer the tutor's same, initiating question to move on with the work of the tutorial. His visit was a class requirement. He needed a tutor's signature for his visit to submit to the class instructor and cannot leave the Center just because his request was not accepted. As a first-time visitor, he does not appear to have any other tactics developed to get proofreading either. The tutee has no other way to move on to the work of the tutorial than following the tutor's suggestion of "talking about grammar."

Bill accepts his second formulation of how he wants to be helped, and it is an acceptable service that the Center can provide. The tutor makes sure of his understanding of what Sang-Jin is concerned about by reformulating his request (lines 35-36). Sang-Jin immediately replies with agreement in line 37. Their understanding of the formulation of how the tutee wants to be helped for his assignment was confirmed with each other. Bill confirms the tutee's agreement (line 38) and begins to talk about "tense," which is an acceptable instruction that the Center can provide.

From the misperception and the lack of knowledge of the work of the Center, the novice L2 tutee made a proofreading request that the Center does not provide and it was refused by the tutor. The tutor made an immediate suggestion of what they can do instead, which became the next course of action and also an immediate instruction for the novice tutee about what the writing center can provide. With the tutee's agreement to the suggestion, they were able to move on with the work of tutorial in a way to be acceptable to the Center's policy. The novice L2 tutee's forbidden request for proofreading was steered to the way that the Center can serve. ${ }^{1}$

Case 2: Are you wanting me to just look at the surface sorts of things?

Many L2 writers come to the Center with their own expectations based on their self-assessment of their writing. When their self-evaluation does not agree with the tutor, the different expectations and the intentions about the tutorial come to the surface of their work and they need to negotiate how to move on to the work of the tutorial. However, those who come to the Center at the last minute before the assignment due with the belief that they have no severe mistakes other than grammar, resist the tutor if the tutor points out higher-level problems that require significant revision, which occurs in many cases. They do not want to cooperate with the tutor in doing the unexpected work.

The second exemplary case is about an L2 novice tutee who hides her request for proofreading until the last minute of the work for the tutorial. The tutor started the tutorial by explaining the instructor's comments on the paper, assuming that the tutee came to get advice how to revise her paper. However, it turned out that the tutee brought two different drafts - the original draft that had her instructor's comments and her newly revised one. She wanted to get a grammar check for her new revised draft. We will see how their two different expectations are played out and how it steers the direction of the tutorial.

Jiao is from China, and this is her second visit to the writing center with the paper from the class of English 110. After her first visit to the writing center, she said that she received an A for the initial draft that she had been working on for English 110. Jiao made her second visit with the original draft on which she had received her instructor's comments and her revised draft. She needed to submit her revised draft that day. Steve, the tutor (a graduate student and English native speaker with three years of tutoring experience) had been providing suggestions on how to revise the original draft that the student showed initially to him based on what the instructor had asked. The Center's primary approach to the course instructors in relation with the tutee is not to

\footnotetext{
1 A part of the transcripts 1-1\& 1-2 was introduced and published as "Could you check my grammar? The forbidden request in the university writing center”, in International Journal of Research Studies in Language Learning, 2018 Volume 7, Number 4, in pages 21-37.
} 
Kim, J.

be against them. When the tutee brings his/her paper for revision with the instructor's comments (sometimes grades as well), the tutor reads the instructor's comments and tries to help the tutee to understand the problems and based on them, the tutor provides the suggestions for revision. Reading the instructor's comments as a reference, Steve makes suggestions for revision. When he is about to move in the text from paragraph to paragraph for detailed comments on the draft, Jiao takes out her revised version and says that she wants only proofreading for her draft.

Transcript 2-1

123 T: I think at this point what that actually looks like ends up being

124 with what the argument is actually about (.) in any case (.2)

125 ((with hand gesture)) what I would do here (.2) then (.2) is (.1)

126 you can try to structurally figure out which arguments are

127 working for him and which argument aren't (.1)

128 T: U:m (1.4) ((T, looking at the paper)) clarifying the fact that- that this isn't-

129 he's not (.) shooting her(.) he's shooting(.) (h) um(.) her mom

$130 \quad \mathrm{C}$ : ((Takes out her revised version of the paper for the first time))

131 I have provided it (.2) and he said it's okay (.hh)

$132 \mathrm{~T}: \quad=$ Okay

$133 \mathrm{C}$ : ((C, pointing at the paper $)) \mathrm{U}: \mathrm{m}$, to revise the part ( ) is okay

$134 \mathrm{~T}$ : =Okay so what- what can I - I mean it sounds to me like

135 you're still happy with your argument //and so: so-

$136 \mathrm{C}$ : $\quad / /($ giggling $))$

137 T: If you're- if you're- if you don't want (.1) to change your argument he-he

138 Are you wanting me to just look at the surface // (0.4) sorts of things

139 C: I/Ea::::yee:: U:::u:::aw::

140 T: in terms of grammar and stuff?

$141>\mathrm{C}:=\mathrm{Y}(. \mathrm{hh}) \mathrm{e}:$ :yah

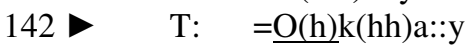

143 C: ((giggling))

144 T: I think that-(.1) I think he has problems with things that are

$145 \mathrm{C}:=\mathrm{U}::: \mathrm{hh}$

146 T: deeper than that(.) based on him telling you (.) He said- well- he said

147 don't' do grammar until you take care of (.)these larger issues (.)

148 Now I guess if you think you can take care of them(.hh)

149 but then- then- we can- we can-

150 we can take a look at at- at- um um

$151 \quad((\mathrm{~T}$, reading her paper line by line $))$

In line 123, Steve has been explaining the instructor's comments and what to do for revision. Then he was moving on to the line that shows incorrect information about the story of Jiao's primary source, Peter and the Wolf, in line 129. Jiao then takes out her revised draft, which is already written and says that she had revised it and he (the instructor) said that it's okay (lines 130-131). The tutor's instruction provided so far for revision was dismissed and Jiao claims that the revision was already confirmed as good by the instructor. For her, no further work for revision is needed. Steve is confused about which direction to move for the work of the tutorial, and he sees that Jiao does not seem to have any intention to change her argument. As soon as Steve says in line 135, "You're still happy with your argument," Jiao's giggling overlaps Steve's perplexed stumbles. Her giggles show that she finally acknowledges that her true motivation for a visit was revealed, which is proofreading, and that she does not need any further suggestions for revision from the tutor.

For Steve, this is a decisive moment. If, as Jiao claims, the revised draft is acceptable to the instructor, the tutor has no further work to do on that issue. The work of this tutorial should be re-directed. From the confusion of what to do next, Steve asks Jiao directly to make sure what she wants, "Are you wanting me to just look at the surface (0.4) sorts of things in terms of grammar and stuff?" (lines 137-138). Jia's awkwardly elongated stuttered "Ea::::yee:: U:::u:::aw::" is overlapped just right after the tutor's word "surface" (line 138)." The tutor completes his questions clearly "in terms of grammar and stuff?" Jiao agrees with him immediately with the stutterd 
"Y(.hhh)e::yah" in line 141. It sounded reluctant a bit but it is a clear confirmation of what she wants from this tutorial. Steve accepts her answer, but with a grudging sense of disappointment in line 142. At this moment, Steve has no other option to work on this tutorial. Jiao knows that Steve is not happy with her request for proofreading but that's what she wants. She giggles from guiltiness.

Unavoidably, Steve accepts Jiao's request for proofreading. Now his job as a tutor is transformed. However, Steve believes that grammar is the last issue to take care of for her revision and says his concern based on the instructor's comments (lines 144, 146-147). Both the tutor and the tutee claim that they are on the same side with the instructor in terms of how to revise the paper. But what they can do for the next action is just proofreading. He moves on to reading her paper for proofreading. He does not have any other course of action to move on to at this moment.

\section{Transcript 2-2}

$151 \quad((\mathrm{~T}$, reading her paper line by line $))$

152 T: (10.0)

153 Ah if mountains is plural(.) we want(.) in the mountains

$154 \mathrm{C}: \quad=\mathrm{Uh}$

155 T: So either $\underline{\operatorname{in}(.)}$ with an $\underline{\mathrm{s}}($.$) or \underline{\mathrm{on}}($.$) with a singular$

$156 \mathrm{C}:=\mathrm{Uh}$

157 T: Um because (.) it's just(.) spatially you can't be on (.)

158 more than one mountain

$159 \mathrm{C}: \quad=\mathrm{U}: \mathrm{h}$

$160 \mathrm{~T}:=$ At the same time which

$161 \mathrm{C}: \quad=$ Uh yeah

$162 \mathrm{~T}$ : [sounds deeply philosophical

163 C: [Yeah ((giggling))

$164 \mathrm{~T}$ : You cannot be on more than one mountain at the same time(.hhh)

165 Chu chu chu chu chu chu chu chu chu

$166 \quad((\mathrm{~T}$, continue reading her paper in silence $))$

He points out grammar problems and provides the corrections in lines 153 and 155. Jiao marks her receipts in lines 154 and 156. Steve provides the explanation of the correction in lines 157-8. Jiao marks her receipts. Steve jokes around what he said about the preposition 'in' and 'on' with singular and plural forms of the noun, 'mountain' (lines 164). Jiao giggles with him. Steve continues reading the paper.

Jiao brought her final draft and seemed to have no intention to revise it. Since her revision has already been completed based on the comments from the instructor, instead of taking Steve's suggestion for revision, she showed the revised version of her paper, which she did not show until the tutor was literally pointing to the line of the passage on the paper. She stopped the tutor from giving help by refusing it and claiming that she does not need 'the help.' For Jiao, the revision has been done. What she wants now at this moment is just a quick fix regarding grammar to make her paper error-free.

\section{Findings}

\subsection{L2 Writer's Perception of Revision and the Writing Center's Instructional Approach}

Second language (L2) writers have a tendency to perceive the revision process as a way to clean all the surface errors from their text. While the more skilled L2 writers are more concerned with higher-order revisions, the less skilled L2 writers are the opposite in their concerns (Craig, 2016; Praphan \& Seong, 2016; Skibniewski \& Skibniewska, 1986; Hirose \& Sasaki, 1994; Sasaki \& Hirose, 1996; Victori, 1999). In this regard, it is not surprising that the less skilled L2 writers who visit the Center with their papers will expect proofreading activity to get an error-free paper from the tutorials and this expectation is where the tutor's dilemma begins.

Bill, who had been tutoring for three years in the writing center said that it is sad to do proofreading when it 
Kim, J.

is the only concern for which the student wants to be helped from the tutorial for their paper. For those who never experienced one-on-one conversational writing instruction in their former education, asking for help for their course paper other than for proofreading, particularly from a tutor who is not an expert in their eyes may not look desirable. Their lack of understanding of the writing tutorial stems from the lack of experience of English writing instruction in their former education. Their former writing practice is heavily focused on the lower order problems of grammar accuracy and syntactic fluency, rather than the higher order problems of structure and organizational issues, which lead to their requests for help from the writing center for proofreading at the last minute before their submission once they finish their paper. Their belief about the writing practice and the tendency for the proofreading request are bound to lead to tensions and conflicts between the tutor and the tutee in their negotiation of how to work in the tutorial. When there is a more urgent need to work on higher-order problems, the student's strong request to proofread to finish his or her paper for submission becomes an obstacle that interferes with the work of the tutorial.

L2 students' concern about grammatical issues is understandable in that it is due to the writing instruction they received previously and which are the most easily noticeable errors that could draw attention. However, when there is little room for consideration of higher order writing issues, in other words, when the negotiation between the tutor and the tutee fails, usually the students themselves become the victims of their narrowly defined belief about writing instruction. Therefore, when the students do not have knowledge of process-oriented writing that requires multiple stages of writing instruction, the tutor's first task becomes convincing the students of the new instructional approach (Ferris \& Hedgcock, 2014; Ferris, 2009). When the students do not have an understanding of the collaborative process-oriented approach of writing instruction, no proofreading simply means that there is no benefit from the tutorial. When they find that they can't get the help that they expect from the tutorial, their disappointment interferes with the tutorial, in which case they may not come back for further instruction as there is no reason for them to do so. As a result, the chances decrease for future assistance to improve their writing to become better writers.

What is required in this situation is the need for international students to comprehend and adjust to the nature of the writing center tutorials. This is crucial for them to receive proper assistance from the tutorials. Some find a way to mediate and adapt to the actual work of writing centers, but some fail to do so and struggle with the work of the tutorial. In the worst case, they may never return to the writing center even if they need help with future writing assignments.

\subsection{Mismatched Expectations of the Work of Tutorial and the Tutor's Dilemma}

Learners' cultural background and their past learning experience influence their learning style significantly (Wong \& Hyland, 2017; Hyland, 1994). So working with the students who come from different social and cultural backgrounds is difficult in terms of figuring out their expectations and their learning styles. Along with the barrier of different languages and cultural backgrounds, mismatched expectations of the work of the tutorials become an obstacle in their interaction during the tutorial.

The mismatched expectations between the tutor and the tutee about the work of the tutorial come from different motivations, and their different motivations influence the work of the tutorial differently. When their motivations are oriented in different directions, their actions for the expected course of the tutorial become incongruent. For the writing tutorials with L2 students, which concern - higher order or lower-order concerns to put as their priority for the tutorials is one of the major issues that bring conflict to the tutorials. The tutor has to negotiate on what to focus on and how to work with the resisting students. This becomes an extra burden on the tutor to work with in addition to the cultural and language differences.

Particularly, those students who come to the writing center at the last minute before they submit a paper have a strong tendency to show resistance to the tutor's suggestions for revision. This also puts the tutor in the difficult position of providing feedback that is limited in scope. In this way, the L2 students lose the chance to 
Same bed, different dreams: the mismatched expectations about proofreading in the writing center

improve their writing, which definitely frustrates the tutor as well. Natalie, who had been tutoring in the writing center for three years stated, "They (L2 students) want to focus on their lower-level problems, but there are bigger problems" (Kim, 2014). However, as case 2 illustrates, the problems of higher-order issues do not always come as a matter of concern to L2 students. The tutor needs to work for an agreement first with the resisting tutee about what to focus on for the tutorial, which is not easy. When the negotiation for an agreement for the tutorial fails, the tutor suffers. The tutor has to either follow what the student wants, or, in the worst case, the student leaves the cubicle. Either way, the tutor becomes frustrated.

The smooth way to move on is just to follow what the tutee wants and give it to them regardless. But when they do that, they know it is not good for anybody - tutor, tutee, and their writing. It does not help the tutees to improve their writing. Knowing all the harmful effects of proofreading in this situation, it is not surprising to hear that the tutors are sad to do proofreading simply because there is nowhere to move on for the next course of action. When the tutor and the tutee come to the tutorial with different dreams in their mind, especially if they are so firm and strong in their belief that they cannot yield any step - one (the tutee) who is trying to get proofreading and the other (the tutor) who is trying not to give proofreading - it becomes tough to negotiate.

\section{Conclusion}

The tutorial in the writing center is conversation-based writing instruction. Whether the focus of the instruction is higher-order concerns or lower-order concerns, the instruction is provided by talk, not by text. So, those who never experienced conversation-based, student-centered writing instruction can be overwhelmed by the new instructional style in terms of how to work with the tutors and what to ask for help when they are asked what they want from the tutorial on their visits. Therefore, the tutees can ask something that they are concerned about, which is a grammar check for proofreading, and this is where the conflict between the tutor and the tutee begins. Dealing with a proofreading request becomes the first task that the tutor needs to take care of for the work with L2 writers. Without dealing with this problematic request, no further meaningful instruction can be provided. In this regard, the proofreading request is the most palpable discordance between the pedagogical philosophy of the writing center and the L2 writers' perceptions about writing instruction.

In order to provide the appropriate instruction for L2 writers to improve their writing ability, understanding their desires and motivations for proofreading is critical to start the work of writing instruction. Pre-service and in-service training programs about the characteristics of L2 writers and the developmental specificity of L2 writing are required for tutors to learn how to work with L2 writers. Also, instructive orientations about the general conventions for academic writing and the process of writing instruction that includes the three phases planning, drafting, and revising - should be provided to L2 writers beforehand during the freshman orientation in order for them to learn how to get help properly when they encounter any problems with writing and the writing assignments.

Concerning the international writing centers outside of the US, there have been a few studies that reported struggles with adapting the US writing center model (Lee, 2014; Bräuer, 2009; Archer, 2007; Turner, 2006; Harbor, 2003; Santa, 2002). The struggle with adapting the theory and practice of the US model, which is focused on process-oriented, conversation-based instruction is not surprising. Different from the US writing center, the tutors in the international writing centers are oftentimes multilingual tutors who have various social, cultural and educational backgrounds (Harbord, 2003; Santa, 2002), and the tutees are mostly faculty or graduate students who prepare for academic journal publication (Turner, 2006), not undergraduate students for peer tutoring as usual in the US. The writing centers in Europe experienced difficulty in adopting the strategies of the US writing center (Harbord, 2003; Santa, 2002) and developed theory and practice toward very specific purposes, such as serving primarily as research centers, curriculum designers, and professional writing trainers (Bräuer, 2009). The different social, cultural and educational backgrounds of the English writing curriculum in different countries became a hindrance to import the US model of the writing center (Archer, 2007; Bawarshi \& Pelkowski, 1999). 
In this light, employing one-on-one conferences in writing class and including speaking activities to develop writing where the students can transform their thoughts to text through talk could be helpful for students to engage the speaking activity in their writing practice, either in their native language or in the target language (McCann, 2014; Rubin \& Kantor, 1984; McCleary, 1979; Troyka, 1973). Lastly, more data-driven empirical studies in the talk-in-interaction during the one-on-one writing tutorial will be necessary for further investigation about this ongoing issue that occurs with L2 writers in the writing tutorial.

\section{References}

Archer, A. (2007). Critical Access to higher education: challenges and goals for South African writing centers. Writing Lab Newsletter, 32(3), 1-6.

Başöz, T. (2014). Through the eyes of prospective teachers of English: Explicit or implicit grammar instruction? Procedia - Social and Behavioral Sciences, 12(103).

Bawarshi, A., \& Pelkowski, S. (1999). Postcolonialism and the idea of a writing center. Writing Center Journal, 19(2), 41-58.

Bräuer, G. (2009). The role of writing in higher education in Germany. In S. Bruce \& B. Rafoth (Eds.), ESL writers: A guide for writing center tutors (pp. 186-194). Portsmouth, NH: Boynton/Cook.

Craig, J. (2016). Unfamiliar territory: Tutors working with second language writers on disciplinary writing. In S. Bruce \& B. Rafoth (Eds.), Tutoring second language writers (pp. 213-234). Colorado: Utah State University Press.

Deckert, S. K. (2009). A(n)/the/0 article about articles. In S. Bruce \& B. Rafoth (Eds.), ESL writers a guide for writing center tutors (2nd ed., pp. 105-115). NH: Boynton/Cook Publishers, Inc.

Dvorak, K. (2016). Multilingual writers, multilingual tutors: Code-switching/mixing/meshing in the writing center. In S. Bruce \& B. Rafoth (Eds.), Tutoring second language writers (pp. 101-122). Colorado: Utah State University Press.

Ferris, D. (2009). Teaching college writing to diverse student populations. Ann Arbor, MI: University of Michigan Press. https://doi.org/10.3998/mpub.263445

Ferris, D. R. (2003). Response to student writing: Implications for second language students. New York: Routledge.

Ferris, D. R., \& Hedgcock, J. S. (2014). Teaching L2 composition purpose, process, and practice (3rd ed.). New York: Routledge.

Harbord, J. (2003). Minimalist tutoring-an exportable model? Writing Lab Newsletter, 28(4), 1-5.

Harris, M., \& Silva, T. (1993). Tutoring ESL students: Issues and options. College Composition and Communication, 44(4), 525-37. https://doi.org/10.2307/358388

Hinkel, E., \& Fotos, S. (2002). New perspectives on grammar teaching in second language classrooms. New York: Routledge.

Hirose, K., \& Sasaki, M. (1994). Explanatory variables for Japanese students' expository writing in English: An exploratory study. Journal of Second Language Writing, 2, 203-229. https://doi.org/10.1016/1060-3743(94)90017-5

Hyland, K. (1994). The learning styles of Japanese students. JALT Journal, 16(1), 55-74.

Kim, J. (2014). Better writers or better writing? A qualitative study of second language writers' experiences in a university writing center [Unpublished Doctoral Dissertation]. The Ohio State University.

Kim, J. (2018). Could you check my grammar? The forbidden request in the university writing center. International Research Studies in Language Learning, 7(4), 21-37.

Lai, P. C. (1986). The revision processes of first-year students at the national university of Singapore. RELC Journal, 17(1), 71-84. https://doi.org/10.1177/003368828601700105

Lee, A. S. (2014). A transcultural framework proposal for international writing centers. In E. Doman (Ed.), Insight into EFL teaching and issues in Asia (pp. 129-146). Cambridge, UK: Cambridge Scholars.

Ling, Z. (2015). Explicit grammar and implicit grammar teaching for English major students in university. Sino-US English Teaching, 12(8), 556-560. 
Same bed, different dreams: the mismatched expectations about proofreading in the writing center

Linville, C. (2009). Editing line by line. In S. Bruce \& B. Rafoth (Eds.), ESL writers a guide for writing center tutors (2nd ed., p. 116-131). NH: Boynton/Cook Publishers, Inc.

Liu, P. E. (2016). These sentences sounded like me: Transformative accommodation in L2 writing. In S. Bruce \& B. Rafoth (Eds.), Tutoring second language writers (pp.180-185). Colorado: Utah State University Press.

Lunsford, A. (1991). Collaboration, control, and the idea of a writing center. Writing Center Journal, 12(1), 3-10.

Markee, N. (2000). Conversation analysis. Mahwah, NJ: Lawrence Erlbaum Associates, Publishers.

Markee, N. (2004). Zones of interactional transition in ESL classes. The Modern Language Journal, 88, 583-596. https://doi.org/10.1111/j.0026-7902.2004.t01-20-.x

Markee, N. (2009). Toward a learning behavior tracking methodology for CA-for-SLA. Applied Linguistics, 29(3), 404-427. https://doi.org/10.1093/applin/amm052

McCannn, T.M. (2014). Transforming talk in to text: Argument writing, inquiry, and discussion, grades 6-12. New York: Teachers College Press.

McCleary, W. C. (1979). Teaching deductive logic: A test of the Tolumin and Aristotelian models for critical thinking and college composition. DAI, 40, 1247.

Min, Y.-K. (2016). When "editing becomes "educating” in ESL tutoring sessions. Praxis: A Writing Center Journal, 13(2).

Myers, S. (2003). Reassessing the proofreading trap: ESL tutoring and writing instruction. The Writing Center Journal, 24(1), 51-70.

North, S. (1984). The idea of a writing center. College English, 46(5), 433-446. https://doi.org/10.2307/377047

Parkhurst, C. (1990). The composition process of science writers. English for Specific Purposes, 9, 169-179. https://doi.org/10.1016/0889-4906(90)90006-X

Porte, G. (1997). The etiology of poor second language writing: The influence of perceived teacher preferences on second language revision strategies. Journal of Second Language Writing, 6(1), 61-78. https://doi.org/10.1016/S1060-3743(97)90006-0

Praphan, P., \& Seong, G. (2016). Helping second language writers become self-editors. In S. Bruce \& B. Rafoth (Eds.), Tutoring second language writers (pp. 235-258). Colorado: Utah State University Press.

Reid, J. (1998). "Eye" Learners and "Ear" learners: Identifying the language needs of international student and U.S. resident writers. In P. Byrd \& J. M. Reid (Eds.), Grammar in the Composition Classroom: Essays on teaching ESL for college-bound students (pp. 3-17). New York: Heinle \& Heinle.

Rubin, D., \& Kantor, K. (1984). Talking and writing: Building communicative competence. In C. Thaiss \& C. Suhor (Eds.), Speaking and writing, K-12 (pp. 29-73). Urbana, IL: NCTE.

Sacks, H., Schegloff , E. \& Jefferson, G. (1974). A simplest systematics for the organization of turn-taking for conversation. Language, 504, 693-735.

Santa, T. (2002). Writing center orthodoxies as Damocles'sword: An international perspective. Writing Center Journal, 22(2), 29-38.

Sasaki, M., \& Hirose, K. (1996). Explanatory variables for EFL students' expository writing. Language Learning, 46, 137-174. https://doi.org/10.1111/j.1467-1770.1996.tb00643.x

Skibniewski, L., \& Skibniewska, M. (1986). Experimental study: The writing processes of intermediate/advanced foreign language learners in their foreign and native languages. Studia Anglica Posnaniensia, 19, 142-163.

Takagaki, T. (2003). The revision patterns and intentions in L1 and L2 by Japanese writers: A case study. TESL Canada Journal, 21(1), 22-38. https://doi.org/10.18806/tesl.v21i1.272

Troyka, L. Q. (1973). A study of the effect of simulation-gaming on expository prose competence of college remedial English composition students [Unpublished doctoral dissertation]. New York University.

Turner, A. (2006). Re-engineering the North American writing center model in East Asia. Praxis: A Writing Center Journal, 3(2).

U.S. Immigration and Customs Enforcement. (2016). ICE releases quarterly international student data. Retrieved from https://www.ice.gov/news/releases/ice-releases-quarterly-international-student-data-0

Victori, M. (1999). An analysis of writing knowledge in EFL composing: A case study of two effective and two 
Kim, J.

less effective writers. System, 27, 537-555. https://doi.org/10.1016/S0346-251X(99)00049-4

Weissberg, R. (2008). Critiquing the Vygotskian approach to L2 literacy. In D. Belcher \& A. Hirvela (Eds), The oral-literate connection (pp. 26-45). Ann Arbor: The University of Michigan Press.

Wong, L. L. C., \& Hyland, K. (Eds.) (2017). Faces of English education students, teachers, and pedagogy. New York: Routledge. 


\section{Appendix}

\section{Transcript Notations}

(.) micro pause

(2.0) Timed silence within or between adjacent utterances

// Notes the point at which one speaker overlaps another.

$=\quad$ Notes the ending of one utterance and the beginning of a next without gap or overlap.

- Underlining indicates stress

(.h) Indicates an in-breath

(h) Indicates out breath

- Hyphens indicate a word cut off in its production

* * Notes soft speaking

: A colon indicates a sound stretch on a word or word portion

( ) Empty indicates an unheard utterance

(( ))Double parentheses contain descriptions of the scene

[ Left bracket indicates a simultaneous start by two speakers

] Right bracket indicates two utterances ending simultaneously 
Kim, J. 